\title{
Transplantation in autosomal recessive polycystic kidney disease: liver and/or kidney?
}

\author{
Jayanthi Chandar $\cdot$ Jennifer Garcia $•$ Lydia Jorge • \\ Akin Tekin
}

Received: 31 January 2014 / Revised: 13 May 2014 / Accepted: 11 June 2014 / Published online: 13 August 2014

(C) IPNA 2014

\begin{abstract}
Autosomal recessive polycystic kidney disease (ARPKD) is characterized by enlarged kidneys with dilated collecting ducts and congenital hepatic fibrosis. There is a variable rate of progression of kidney and liver disease. Portal hypertension and Caroli's disease occur from liver involvement that contributes to morbidity and mortality. Approximately $40 \%$ of patients have a severe disease phenotype leading to rapid onset of end-stage kidney disease (ESKD) and signs of portal hypertension and the rest may have predominant involvement of either the kidney or liver. It is important for the physician to establish the extent of organ involvement before deciding on the ultimate plan of management, especially when transplantation is required. Isolated renal transplantation can be considered when liver involvement is minimal. If hepatobiliary disease is prominent, and kidney function is preserved, management options are based on individual characteristics. In the presence of significant liver disease and ESKD, consideration should be given to combined liver kidney transplantation, which can be beneficial in eliminating the consequences of both kidney and liver
\end{abstract}

\section{J. Chandar $(\bowtie)$}

Department of Pediatrics, Division of Pediatric Nephrology, Holtz Children's Hospital, University of Miami Miller School of Medicine, PO Box 016960 (M-714), Miami, FL 33101, USA

e-mail: jchanda2@med.miami.edu

J. Garcia

Department of Pediatrics, Division of Pediatric Gastroenterology, Holtz Children's Hospital, University of Miami Miller School of Medicine, Miami, FL, USA

\section{Jorge}

Department of Anesthesiology, University of Miami Miller School of Medicine, Miami, FL, USA

A. Tekin

Department of Surgery, Division of Transplantation, University of Miami Miller School of Medicine, Miami, FL, USA disease. However, this is a complex surgical procedure that needs to be performed at experienced transplant centers. Improvement in surgical techniques has considerably improved short-term graft survival with the added advantage of the liver offering immunologic protection to the kidney allograft.

Keywords ARPKD · Combined liver kidney transplant . Children · Congenital hepatic fibrosis

\section{Introduction}

Autosomal recessive polycystic kidney disease (ARPKD) is a fibrocystic disease that affects both the kidney and liver. It is caused by mutations in the PKHD1 gene that is located on chromosome 6 and encodes a protein fibrocystin/polyductin found in primary cilia of renal tubular and biliary epithelial cells [1-5]. The disease is heterogeneous and characterized by fusiform dilatation of renal collecting ducts and dysgenesis of hepatic biliary ducts. Fifty percent of the patients affected manifest in the neonatal period [2]. The rest are recognized later and can present at any time from infancy to adulthood.

Polycystic kidney disease and congenital hepatic fibrosis are the most common clinical manifestations of the disease [4-6]. Pancreatic cysts and cerebral aneurysms have been rarely described in single case reports [7-10]. Individuals with two truncating mutations have a severe clinical phenotype, whereas those with amino acid substitutions have a less lethal presentation [4]. However, there is wide variability in the onset of clinical manifestations and rate of progression of kidney disease even in patients carrying the same PKHDI mutation, suggesting modifying genes and environmental factors play an important role in phenotypic presentation [4]. 


\section{Clinical presentation}

Antenatal and neonatal presentation is characterized by the presence of markedly enlarged kidneys, resulting in respiratory compromise and limitations in enteral feeding. Thirty percent of affected neonates die from respiratory failure and pulmonary hypoplasia [2]. Neonates with large echogenic kidneys have ectasia of $60-90 \%$ of the renal collecting tubules and generally have hypertension and decreased kidney function $[1,2]$. Beyond the neonatal period, hypertension occurs early in two-thirds of children [1]. There is a variable rate of progression of kidney and liver disease. Children may have advanced failure of more than one organ or predominant failure of one organ with a wide range of clinical severity. Kidneys with ARPKD do not increase in size after the first 23 years of life $[1,2]$. Those with corticomedullary involvement versus only medullary involvement have worse kidney function [11]. Survival into mid-adulthood without requiring liver or renal replacement therapy has been described $[12,13]$. There is also considerable intra-familial variability [4].

Fetal morphologic studies have revealed malformation of the biliary ductal plate and associated abnormalities of the portal veins in ARPKD [14, 15]. Ductal plate malformations occur as a consequence of derangement in remodeling of the developing fetal biliary ductal system. A spectrum of pathologic biliary abnormalities can occur ranging from extrahepatic choledochal cysts to intrahepatic ductal dilatation and cyst formation. Ductal plate malformations result in persistence of primitive bile ducts, aberrant interlobular bile duct proliferation, and expansion of portal areas with an excess of embryonic bile ducts and fibrous tissue. Caroli's disease is characterized by non-obstructive, segmental, communicating saccular or fusiform dilatation of the large intra-hepatic bile ducts [16]. The defect may be localized or diffuse. When both Caroli's disease and congenital hepatic fibrosis occur, it is termed Caroli's syndrome.

Hepatocellular dysfunction is rare, and when present, is not typically seen until late. However, portal hypertension and abnormalities of the biliary tract are common and manifest long before loss of synthetic function of the liver. Overt clinical manifestations of hepatobiliary disease have been noted in $46-83 \%$ of children [2-4]. The signs are hepatic enlargement or heterogeneous and echogenic appearance of the liver by ultrasound, splenomegaly, hypersplenism, esophageal varices, protein-losing enteropathy, and ascending cholangitis [2,3]. Enlargement of the left lobe of the liver is a consistent finding [11]. Patients with Caroli's disease are at risk for acute bacterial cholangitis leading to septicemia and biliary tract calculi from stasis. Gram-negative organisms and occasionally Gram-positive anaerobes and fungi are implicated in acute cholangitis requiring broad-spectrum antibiotic coverage [17]. Fever, right upper quadrant pain, icterus, and abnormal transaminases could indicate cholangitis but often the presentation can be subtle. A significant number of children have succumbed to the complications of biliary disease after transplantation [18-21]. Extrahepatic biliary disease as the predominant manifestation has also been reported [9]. Ascites, hepatopulmonary syndrome, portopulmonary disease, and hepatic encephalopathy are less common. The development of ascites should herald further evaluation for other underlying issues such as portal vein thrombosis or loss of peritoneal exchange space caused by recurrent peritonitis [3]. Hepato-pulmonary syndrome is a complication of portal hypertension and is characterized by impaired oxygenation in the upright position, intra-pulmonary vascular dilatations, and the presence of portal hypertension. This has been described with congenital hepatic fibrosis $[22,23]$.

The following case scenarios reflect the heterogeneity of clinical presentation.

Case 1 A 5-year-old Hispanic male was diagnosed with ARPKD soon after birth when he was noted to have mild renal insufficiency and hypertension. He had a progressive and rapid increase in kidney size resulting in feeding difficulties and decreased respiratory reserve. In order to facilitate and optimize feedings, a left nephrectomy was performed at 7 months of age, after which his serum creatinine increased from 0.8 to $1.2 \mathrm{mg} / \mathrm{dl}$. Thereafter, he had progressive deterioration of renal function and worsening hypertension. He had a right nephrectomy at 16 months of age and was placed on peritoneal dialysis for 1 year. Following an episode of fungal peritonitis, he was switched to hemodialysis. He was noted to have hepatosplenomegaly and hypersplenism at the age of two and had intermittent elevations of liver enzymes during periods of acute illness. Liver biopsy was consistent with congenital hepatic fibrosis and early cirrhosis. He had no episodes of gastro-intestinal bleeding. Magnetic resonance cholangiopancreatography (MRCP) revealed mild dilatation of the intra-hepatic biliary ducts and high T2 signal intensity throughout the periphery of the liver. Therefore, with clinical evidence of portal hypertension, the consensus was to list him for a combined liver kidney transplant. At an age of 3.5 years, (weight $13.5 \mathrm{~kg}$ ), he had a combined "en bloc" liver kidney transplant. Pathologically, the liver was described as being cirrhotic with intraductal cholestasis (Fig. 1a and b). He is currently 2 years post-transplant and doing very well with a serum creatinine of $0.3 \mathrm{mg} / \mathrm{dl}$ on a single immunosuppressive regimen of tacrolimus.

Case 2 An 18-year-old Caucasian female presented at age 6 months with a urinary tract infection (UTI) and was found to be hypertensive. Ultrasonography revealed large echogenic kidneys, and she was 
A

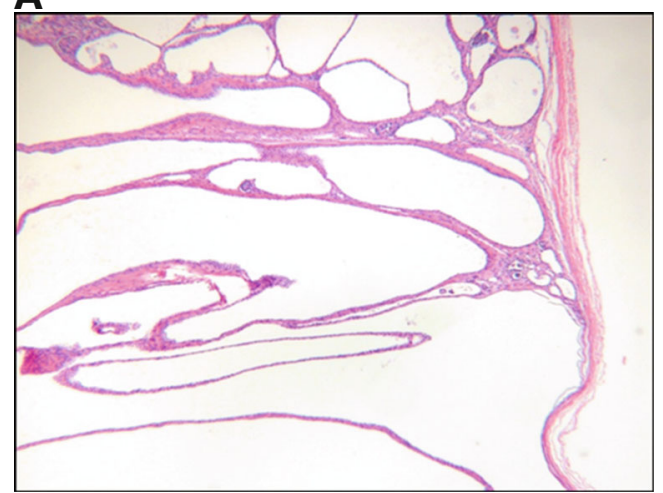

B

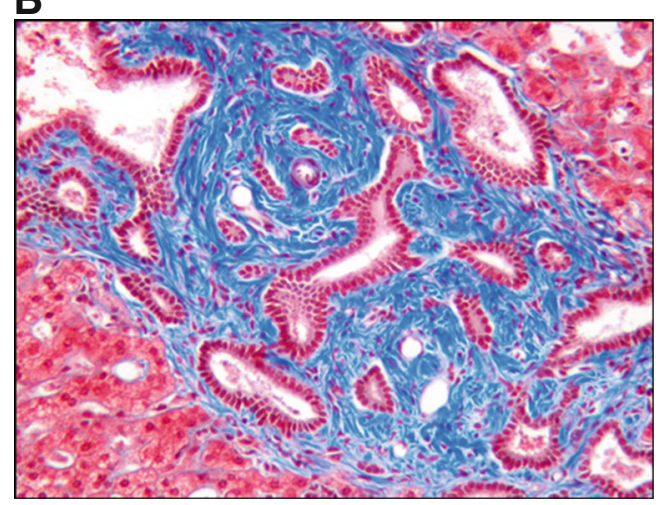

Fig. 1 a Anatomic pathology of the kidney of a 5-year-old boy with autosomal recessive polycystic kidney disease (ARPKD). He had nephrectomies done at 6 months and 16 months of age. The collecting tubules show marked ectasia and are radially oriented and perpendicular to the capsule. b The liver in the same patient reveals hyperplastic and dysgenetic biliary ducts with cystic dilatation and peri-portal fibrosis. He had clinical evidence of portal hypertension. Therefore a combined liver kidney transplant was performed at the age of 3.5 years

diagnosed with ARPKD. She had recurrent UTI in early childhood. Renal insufficiency was noted at age 10. She progressed to advanced chronic kidney disease at age 17. She had no splenomegaly, hypersplenism, or esophageal varices. Her liver biopsy was normal. MRCP revealed extrahepatic and intra-hepatic biliary dilatation. Therefore, an endoscopic retrograde cholangiopancreatography (ERCP) was done which revealed narrowing of the distal end of the common bile duct. A sphincterotomy was performed. The intra-hepatic branches did not reveal the characteristic appearance of Caroli's disease. Genetic testing revealed a known pathologic mutation in the PKHD1 gene. Therefore, this patient is awaiting a pre-emptive kidney transplant.

Case 3 An 18-year-old Hispanic male was diagnosed with ARPKD shortly after birth when he presented with hypertension and UTI. He was managed with angiotensin blockers for his hypertension. At age 14, he was evaluated for abdominal pain and was found to have gallstones and a heterogeneous liver by ultrasound with no intra-hepatic biliary dilatation. Further imaging studies revealed numerous peri-portal and splenic varices and a patent umbilical vein, which were strongly indicative of portal hypertension. $\mathrm{He}$ had gastric varices on upper GI endoscopy. His kidneys were enlarged (13.5 cm bilaterally) with numerous cortical cysts. Liver biopsy revealed congenital hepatic fibrosis with cirrhotic changes and dysgenesis of the bile ducts. His serum creatinine was $0.7 \mathrm{mg} / \mathrm{dl}$. His synthetic liver function was normal. He was a well-grown and tall adolescent. A decision was made for placement of a splenorenal shunt based on his portal hypertension with intact hepatocellular synthetic function and normal serum creatinine. He has stable renal and liver function at the current time.

In the first case, a decision was made for a combined liver kidney transplant based on his ESKD and clinical evidence of portal hypertension. There were several inter-disciplinary team discussions regarding surgical options in this child. If he had an isolated kidney transplant, a porto-systemic shunt could be performed when he developed worsening signs of portal hypertension. However, this could expose this small child to further complications such as shunt thrombosis and could complicate future liver transplantation. A combined liver kidney transplant (CLKT) in this child would give him the benefit of having two organs from the same donor and prevent the consequences of worsening portal hypertension. Moreover, transient elevation of liver enzymes during his febrile illnesses could have been attributed to cholangitis that may have been masked by peritonitis. Therefore, the ultimate decision was to give him a CLKT. This patient has been followed for 2 years since the transplant. The second case had advanced chronic kidney disease with no evidence of Caroli's disease or portal hypertension, but had an abnormality of the common bile duct. This patient has been followed by us for the last 12 years. An MRCP is planned for future follow-up. This patient had no previous history suggestive of surgery or inflammatory disease of the hepatobiliary system that could explain the stricture. The third case had portal hypertension with preserved renal function. An isolated liver transplant could also have been considered in this patient. However, this was deferred so that the option of CLKT could be considered if needed in the future. He has been followed for the last 7 years and continues to maintain stable liver and kidney function. These cases demonstrate the wide variability in phenotypic expression of ARPKD thus illustrating the need to individualize management. The underlying pathophysiologic mechanisms resulting in phenotypical variability are yet to be elucidated. 


\section{Diagnostic work up}

It is important to elucidate the extent of organ involvement to determine optimal management in each patient. If the patient has ESKD, preparation of the patient for transplantation should start many months in advance and include optimization of nutrition, good blood pressure control, and treatment of hyperparathyroidism. An interdisciplinary team of physicians and healthcare providers are involved in preparing a plan of care for each patient. Along with kidney and liver failure, patients with advanced ARPKD may have varying degrees of multiple organ dysfunction. Echocardiography to evaluate cardiac structure and function, qualitatively assess pulmonary artery pressures, and baseline chest X-ray and other pulmonary imaging studies if required, are obtained during the patient's initial evaluation.

Kidneys with ARPKD are very large, have poor corticomedullary differentiation, and grow rapidly in early infancy. As the child grows, the rate of growth of the kidneys slows down. High-resolution ultrasonography helps in determining the extent of renal involvement in patients with milder forms of renal disease where ductal dilatation may be present predominantly in the medullary region [11]. The prevalence of hepatic abnormalities is underestimated in children. Every effort should be made to systematically screen children with the diagnosis of ARPKD for hepato-biliary disease. Investigations in a child with ESKD and ARPKD should be geared towards diagnosing portal hypertension and Caroli's disease (See Fig. 2). Conventional and Doppler ultrasonography to determine the size of the spleen, direction of flow in the portal venous system, liver size and echogenicity, complete blood and platelet count to assess hypersplenism, and upper endoscopy to look for esophageal varices help assess the presence of portal hypertension. Magnetic resonance cholangiopancreatography or triple-phase CT scan are useful tools to assess saccular and cystic dilatation of the intrahepatic ducts, venous collaterals around the portal vein, and a patent umbilical vein. Liver biopsy should be considered and may be helpful in making the diagnosis and to define the magnitude of the liver disease when it is in doubt. However, in the presence of advanced liver disease and multiple liver cysts, liver biopsy is associated with an increased risk of bleeding and infection. A transjugular biopsy may be considered if there is a strong indication. Histological confirmation alone will not help in determining management. Most often, sufficient diagnostic information is obtained based on clinical, laboratory features, and imaging studies.

Hepatopulmonary syndrome (HPS) is a complication associated with portal hypertension and is clinically manifested by hypoxemia in the upright posture and objective signs of arterial blood oxygenation differences due to intrapulmonary shunts (see Fig. 2). Although HPS is recognized with greater frequency in cirrhotic children, it has also been described in non-cirrhotic portal hypertension $[23,24]$. When HPS is suspected, technetium-labeled albumin perfusion scintigraphy and contrast-enhanced echocardiography are useful diagnostic tests to evaluate pulmonary vascular dilatation and intrapulmonary arteriovenous shunts [24].

Genetic diagnosis may be important early in pregnancy when there is an affected sibling or if the diagnosis is in question [2]. The PKHdl gene is a very large gene with a complicated splicing pattern and makes genetic testing time consuming, expensive, and labor intensive. There is marked allelic heterogeneity and most patients are compound heterozygotes [25].

\section{Renal transplantation}

Reports suggest that $7 \%$ of children under 2 years of age, and $10 \%$ of children between the ages 2 and 15 years requiring renal replacement therapy have the diagnosis of PKD (of which $83 \%$ have ARPKD) and range in age from 0.7 to 16.4 years [21]. Although graft and patient survival are comparable between patients with non-PKD versus PKD, sepsis usually related to cholangitis is a major cause of mortality [21]. Portal hypertension seems to occur at an average age of 8.3 years [4]. The general thought is that long-term survivors tend to develop the sequelae of portal hypertension. Beunoyer et al. studied the clinical course of ten patients with neonatal ARPKD. Sixty percent had signs of portal hypertension and Caroli's disease and $30 \%$ had cholangitis [18]. Eighty percent were transplanted prior to age 3 . This suggests that neonatal survivors of ARPKD have a greater propensity to have early signs of hepatic manifestations and have more severe renal involvement compared to those who present after the neonatal period. Recent reports suggest that $40 \%$ of patients with ARPKD have both severe kidney and liver disease $[6,26]$.

\section{Treatment and prevention of variceal bleeding}

Recent expert opinion suggests endoscopic band ligation is favorable over sclerotherapy in eradication of varices [27]. After a first variceal bleed, serial sessions are performed every 2-4 weeks until eradication of varices or a total of five sessions. Re-bleeding, recurrence of varices, and development of gastric varices can occur. Sclerotherapy can be considered in children too small to undergo ligation but is inferior to ligation given increased risks of procedure. There are no current guidelines for primary prophylaxis of the first gastrointestinal bleeding episode. However, endoscopic ligation can be considered when there is an increased risk of morbidity and mortality from the first variceal bleed $[27,28]$. There is no data available on safety and dosing of nonselective betablockers, which are not currently recommended for routine use in children [27]. 


\section{DIAGNOSTIC ALGORITHM FOR MANAGEMENT OF ARPKD}

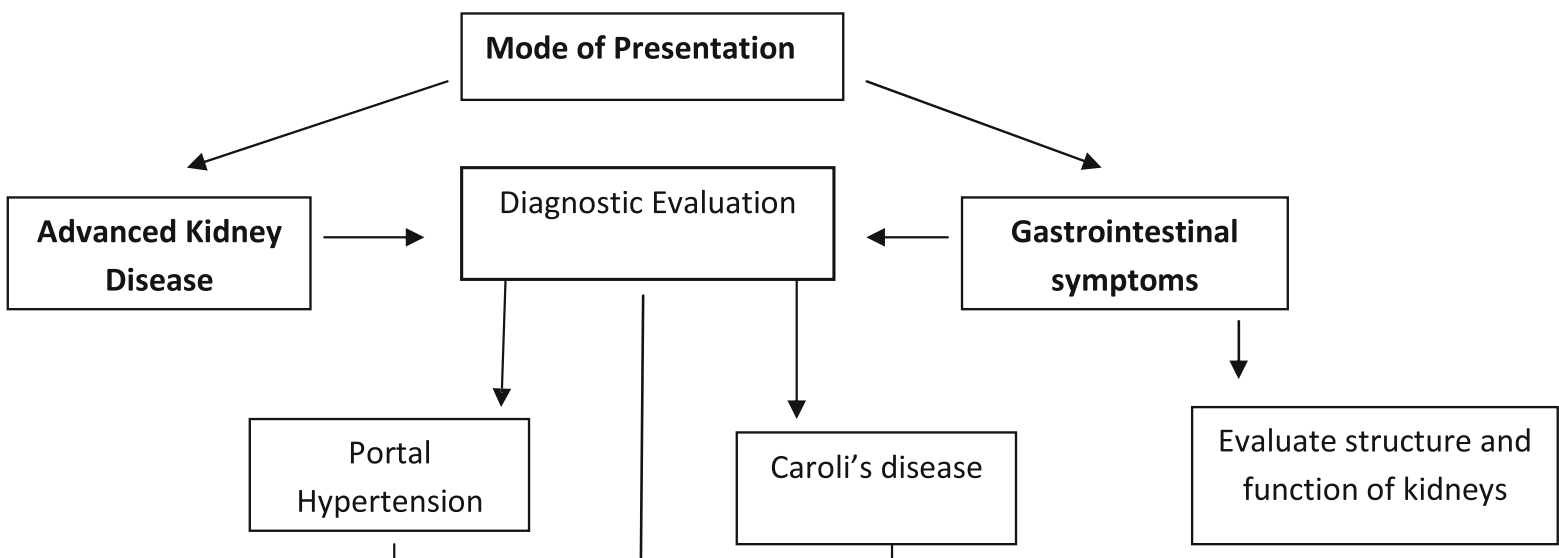

\section{Clinical Signs}

GI bleed

Abdominal distension from

ascites or hepatosplenomegaly

\section{Laboratory}

Leukopenia, thrombocytopenia
Ultrasound- Diffusely echogenic or heterogeneous liver; enlarged left lobe of liver, increased splenic length to height ratio

Doppler ultrasound of portal venous system - hepatofugal flow Upper GI series and endoscopy esophageal and gastric varices Liver elastography - non-invasive test to assess degree of fibrosis in the liver

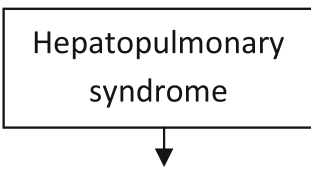

\section{Clinical Signs}

Decrease in oxygen saturation; tachypnea in the upright position

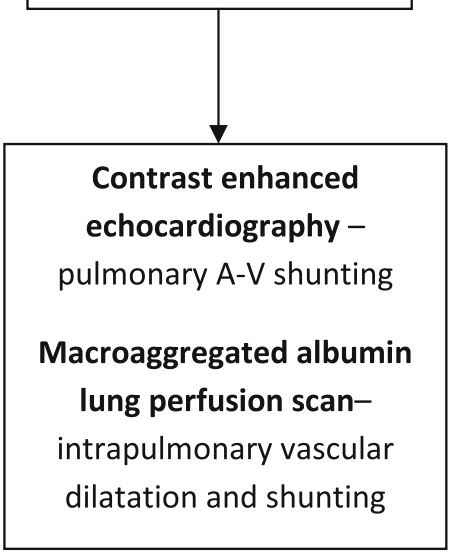

Clinical Signs

Signs of acute cholangitis

Recurrent fever

Biliary tract stones

Laboratory

Elevated bilirubin and transaminases
Ultrasound- Dilated bile ducts or hypoechoic areas in the liver

\section{MRCP or Triple Phase CT scan -}

fusiform or saccular dilatation of intra-hepatic biliary duct and extrahepatic biliary abnormalities

ARPKD, autosomal recessive polycystic kidney disease; GI, gastrointestinal; MRCP, magnetic resonance cholangiopancreatography $\mathrm{CT}$, computed tomography

Fig. 2 Suggested algorithm for diagnostic evaluation of ARPKD prior to transplantation. Clinical manifestations of other organ involvement may not be evident, and need to be investigated so that management can be planned

\section{Portosystemic shunting}

Endoscopic therapies do not alter pressure in the portal system and redistribution of blood can occur at other sites in the portal system [29]. Hence, in patients who fail endoscopic treatment for prevention of re-bleeding, surgical portosystemic shunting is recommended, especially if prognosis is expected to be good within the next 5 years. Transjugular intrahepatic portosystemic shunting (TIPS) can be considered if the patient is considered at a high risk for surgical shunting or as bridge to transplantation in cases of persistent bleeding and poor 5-year expected outcome [29, 30]. Very few porto-systemic shunts 
are reported under the age of 5 years [30-33]. Spleno-renal shunts are the most common and are preferred if orthotopic liver transplantation is considered in the future [32]. Transjugular intra-hepatic porto-systemic shunts, mesenteric portal, and splenorenal shunts have been done in children with a history of recurrent variceal hemorrhage, despite endoscopic ligation of gastric varices. Complications of shunt placement are stenosis, thrombosis, shunt encephalopathy, and revision of shunt with growth of the child [30-32].

Anecdotal reports of management of portal hypertension in children with portosystemic shunts have been reported in ARPKD [33]. However, the kidney is a major source of ammonia disposal in the presence of decreased hepatic ammonia detoxification [34-36]. This compensatory mechanism is limited with significant renal dysfunction. Placement of a shunt in a child with ESKD can increase the risk of hepatic encephalopathy from hyperammonemia [37]. Portosystemic shunt may be considered after successful renal transplantation.

\section{Isolated liver transplantation}

There is increased morbidity and mortality from sepsis associated with cholangitis [38]. If there is no evidence of advanced chronic kidney disease, liver transplantation alone can be considered in the setting of recurrent episodes of cholangitis, which can occur with intrahepatic duct dilatation or associated with Caroli's disease or syndrome [39]. Recurrent episodes of cholangitis can hasten liver damage and biliary cirrhosis. Although cholangiocarcinoma has not been reported in children with ARPKD, adults are at higher risk for this complication. Liver transplantation is indicated in decompensated cirrhosis, refractory portal hypertension, and hepatopulmonary syndrome [39]. Partial hepatectomy can be considered in patients with monolobar Caroli's disease, thus sparing the patient from immunosuppression that is required with orthotopic liver transplantation [40].

\section{Combined liver kidney transplantation}

There are 300-400 CLKT performed in the US each year. Of the 2,819 CLKTs done from 1988 to 2007 , only $4 \%$ were done in children $<18$ years [41]. The indications for CLKT are different in children compared to adults [41-44]. Hyperoxaluria, ARPKD, some rare inborn errors of metabolism and atypical HUS from factor $\mathrm{H}$ mutation, are some of the indications for CLKT in children. The outcome of CLKT appears to be center-dependent, but has been improving even in children weighing less than $15 \mathrm{~kg}$ [26, 45-48]. Some centers have reported a 5-year patient and graft survival of $100 \%$ [46]. The timing of requirement for liver transplantation in ARPKD is extremely variable. About $40 \%$ of patients have severe renal and hepatobiliary phenotype and could be potential candidates for CLKT [6]. Mortality in $60-80 \%$ of patients with kidney transplants from ARPKD is from hepatobiliary disease [21]. Surgical mortality from liver transplantation in recent years has decreased to $<10 \%$ at 1 year. It has been suggested that in a select group of patients, combined liver kidney transplantation is a viable option [48]. Children with ARPKD will not have a high Pediatric End Stage Liver Disease (PELD) score as they have normal hepatocellular function for a long time despite developing portal hypertension and cholangitis. Therefore the PELD score does not adequately reflect the morbidity and mortality associated with cholangitis. An exception has to be requested if a decision is made that CLKT will be beneficial in a given situation.

\section{Technical aspects of CLKT}

Adequate preservation with cold electrolyte solutions and short cold ischemia times are vital for CLKT. Simultaneous or sequential liver kidney transplantation are some of the options. In simultaneous CLKT, the organs are obtained from the same donor. Matching the size of the donor to the recipient is important for post-operative recovery [47]. Whole liver grafts, split grafts, en bloc or reduced grafts are used depending on the size of the recipient. The liver graft is implanted first to shorten the cold ischemia time followed by the kidney, which is implanted extraperitoneally, from a separate incision in the right or left lower quadrant. Alternatively, the kidney can be implanted intra-abdominally. One of the approaches at our institution is to implant the kidney graft $18-24 \mathrm{~h}$ after the liver graft while maintaining the kidney on machine perfusion, which has been demonstrated to reduce preservation injury during reperfusion $[49,50]$. This shortens the surgical time for each organ transplant and allows recovery of the liver transplant. The patient is maintained on CRRT during the interval between liver and kidney transplantation.

Conventional liver transplantation involves clamping of the recipient IVC and portal vein with subsequent removal of the recipient's liver and retro-hepatic vena cava [51]. This is then replaced with the donor segment of vena cava and liver. An alternative approach that has been used is the piggyback technique, wherein the recipient's inferior vena cava (IVC) is preserved and partial clamping of the IVC is possible, thus mitigating the complication of decreased venous return to the heart and venous congestion in the intestinal capillary bed [52-55]. The piggyback technique is associated with a reduction in surgical time and warm ischemia time, decreased need for blood products, and reduction in 30-day mortality [55]. In small pediatric recipients, the organs can be placed "en bloc" where the liver and kidney are harvested with the donor aorta and IVC, which are anastomosed to the recipient aorta and IVC. This is followed by the donor and recipient portal vein 
and biliary tract anastomosis. This technique is advantageous in small recipients with size-matched donors [56, 57].

Peri-operative management of CLKT Both the intra-operative time and post-operative care are significantly longer with CLKT when compared to isolated solid-organ transplantation. Preoperative dialysis helps to optimize a patient's fluid status and electrolyte balance. In addition to standard continuous monitoring of vital signs, central venous pressure (CVP), arterial blood pressure analysis, and expired gas analysis are monitored. Metabolism of neuromuscular blocking agents is prolonged by the degree of liver and kidney dysfunction, and caution should be exercised [58]. Effective communication with the surgical, medical, and operative team is essential to efficiently manage the anticipated hemodynamic and metabolic changes.

Liver resection and transplantation entails a massive loss of blood. Multiple vascular and central venous access are required for rapid fluid and blood product administration. Intra-operative management consists of maintaining hemodynamic stability, electrolyte balance, and maintenance of coagulation [59]. Most patients with ARPKD are anephric. Therefore massive infusions of colloids and crystalloids result in significant fluid overload and hyperkalemia. It is recommended to have washed PRBCs to decrease potassium load. Autologous blood recovery systems such as Cell saver ${ }^{\circledR}$ (Haemonetics Corporation, Braintree MA)are used to recover, and wash lost blood and give this back to the patient [60]. It reduces allogeneic blood transfusion, decreases the potassium content of the transfused blood, and concentrates blood.

CLKT can be technically demanding and time consuming. Varying degrees of hemodynamic instability can be observed throughout the surgery, and the anhepatic phase is most turbulent. Patients with liver disease often develop lactic acidosis, especially in the anhepatic phase. This is worsened by renal failure and is difficult to correct by conventional methods. Hyperkalemia occurs after unclamping of the portal vein during reperfusion of the donor liver resulting in arrhythmias and hemodynamic instability. Pre-existing renal impairment, increased baseline serum potassium, multiple transfusions of blood, and ischemia reperfusion injury contribute to hyperkalemia [61]. Pre-reperfusion flushing of the graft with lactated Ringer's solution is a helpful strategy to ameliorate this.

Intra-operative CRRT Intra-operative renal replacement therapy helps to manage metabolic acidosis and maintain potassium at lower levels. Depending on the hemodynamic status of the recipient, fluid balance can be adjusted. Acute increases in potassium may still need to be managed with drugs that drive potassium intra-cellularly [62]. Since most patients with ARPKD do not have end-stage liver disease, a low dose of anti-coagulation is used to maintain filter patency and this should be communicated with the surgeon. CRRT is started after induction of anesthesia before commencement of surgery. Adjustments are made to the prescription periodically depending on the electrolytes, CVP, and blood pressure. Monitoring hemodynamic status can be a challenge, as CVP may not be reliable because increased intra-abdominal pressures, and positive end expiratory pressure, can affect CVP. Although there are limited indications for the use of pulmonary catheters in children, they can be considered during CLKT, as useful intra-operative data can be obtained from direct measurements of right heart pressures and cardiac output. However, its use is currently limited to pediatric patients with pulmonary hypertension and refractory shock. Transesophageal echocardiography can be an additional tool to determine the dynamic function of the heart and contractility.

Post-operative course In the immediate post-operative period, most patients are in significant positive fluid balance. These patients may need a longer duration of mechanical ventilation compared to isolated organ transplantation [47]. In some instances, the abdominal wall is closed temporarily in small-sized recipients until edema improves. After 2-3 days, the abdominal wall is closed. The patency of the vasculature is assessed on a daily basis by Doppler ultrasound to monitor the possibility of post-operative thrombosis.

\section{Clinical and therapeutic dilemmas}

Overt clinical manifestations of hepatobiliary disease are not evident in all patients with ARPKD who have clinical signs of renal disease and the converse is also true. Therefore it is important to perform a thorough investigation if transplantation or an invasive procedure is being considered, so that appropriate decisions are made. Clinical decision-making is further complicated by the fact that the rate of progression of disease in each organ is variable. It is very difficult to predict the rate of progression of portal hypertension or intrahepatic ductal dilatation. In the case series described from Beunoyer et al., a significant proportion of patients had portal hypertension and cholangitis at baseline [18]. Their group opted to perform isolated kidney transplantation in all of them. Posttransplant, two of ten $(20 \%)$ required surgical intervention for hepatobiliary disease. Khan et al. reported significant morbidity and mortality from cholangitis in their series of children with intrahepatic duct dilatation who had an isolated renal transplant [20]. Each center's approach to transplantation in the very young patient varies. Animal models suggest that intraductal dilatation is a progressive phenomenon and it is unclear if this is also true for human ARPKD. Thus, patients with an isolated renal transplantation have to be closely monitored for worsening of portal hypertension and progression of intrahepatic ductal dilatation. 
One approach to a patient with neonatal or infantile ARPKD and ESKD is to provide a kidney transplant and address the complications of portal hypertension as they arise. One will need periodic screening for esophageal varices, which can be managed with endoscopic band ligation or a portosystemic shunt if indicated. Pancytopenia can be a problem, and may prompt changes in immune suppression leading to increased risk of rejection. Ascites can develop with worsening portal hypertension. At that point, liver transplant can be considered. Recurrent episodes of cholangitis can be associated with considerable morbidity and mortality, especially after isolated kidney transplantation. The typical saccular dilatations of the intra-hepatic biliary system may not develop in very young children. However, they may still be susceptible to cholangitis without overt evidence of Caroli's disease. A crucial question that will need to be answered is if CLKT offers a survival benefit for the patient and graft in children with ARPKD compared to isolated kidney transplantation. Studies in adult populations cannot be extrapolated to the pediatric population as CLKT is done for other indications. Kidney graft survival and rejection-free survival has been shown to be better in CLKT compared to kidney transplantation after liver transplantation [63].

\section{Conclusions}

In a child with ESKD who has no evidence of portal hypertension, Caroli's disease or episodes of recurrent cholangitis, isolated kidney transplantation is a good option. Periodic follow-up for monitoring the development of liver disease is suggested. When portal hypertension is associated with variceal bleeding, but liver and kidney function are preserved, endoscopic band ligation can be considered. If there is a repetitive need for endoscopic band ligation, porto-systemic shunting is an option. Liver transplant is considered in the setting of severe portal hypertension refractory to medical management, Caroli's disease, recurrent cholangitis, or loss of synthetic liver function. In a child with ESKD and overt evidence of portal hypertension and/or Caroli's disease and recurrent cholangitis, combined liver kidney transplantation can be beneficial in eliminating the consequences of both kidney and liver disease in ARPKD. Furthermore, there is evidence that the liver offers immunologic protection over the kidney $[64,65]$. Transplanting two organs from the same donor has been associated with a decreased risk of rejection. The added advantage of a liver transplant is that a single agent can be eventually used for immunosuppression. The benefit of CLKT will have to be balanced with the morbidity, mortality, and complexity associated with this major surgical procedure and the experience of the transplant center.

\section{Questions (answers are provided following the reference list)}

1. Liver disease in ARPKD occurs because of:
a) Abnormalities in the hepatic diverticulum
b) Defective formation of hepatocytes
c) Abnormalities in the development of the hepatic arteries
d) Ductal plate malformations
e) Poor development of the pancreatic bud

2. In a patient with ARPKD and advanced kidney failure, combined liver kidney transplant may be considered in association with which one of these conditions?
a) ESKD
b) Cerebral aneurysms
c) Caroli's disease
d) Recurrent UTI
e) Uremic cardiomyopathy

3. A 4-year-old male with ARPKD has been called for a combined liver kidney transplant. The nephrology team has been requested to do intra-operative CRRT. The purpose of CRRT in this situation would be to:
a) Correct coagulation disturbances
b) Treat cardiac arrhythmias
c) Prevent blood loss
d) Maintain lower serum potassium
e) Lower serum creatinine

4. What percent of children with ARPKD will have both severe kidney and liver disease?
a) $90 \%$
b) $80 \%$
c) $10 \%$
d) $2 \%$
e) $40 \%$

5. Diagnostic testing in a child with ARPKD being considered for transplantation will include all except:
a) Magnetic resonance pancreatico-cholangiogram
b) Upper gastrointestinal endoscopy
c) Doppler ultrasound of the kidney
d) Doppler ultrasound of the portal venous system
e) Chest X-ray

Acknowledgments We thank Dr. Andreas Tzakis for initiating the pediatric program for combined liver kidney transplantation and for his outstanding and unparalleled contributions to the care of children needing liver transplantation. We also thank Dr. Maria Rodriguez, pathologist for the photomicrographs of the liver. 


\section{References}

1. Guay-Woodford LM, Desomond RA (2003) Autosomal recessive polycystic kidney disease: the clinical experience in North America. Pediatrics 111:1072-1080

2. Sweeney WE Jr, Avner ED (2011) Diagnosis and management of childhood polycystic kidney disease. Pediatr Nephrol 26: 675-692

3. Srinath A, Shneider BL (2012) Congenital hepatic fibrosis and autosomal recessive polycystic kidney disease. J Pediatr Gastroenterol Nutr 54(5):580-7

4. Bergmann C, Senderek J, Küpper F, Schneider F, Dornia C, Windelen E, Eggermann T, Rudnik-Schöneborn S, Kirfel J, Furu L, Onuchic LF, Rossetti S, Harris PC, Somlo S, Guay-Woodford L, Germino GG, Moser M, Büttner R, Zerres K (2004) PKHD1 mutations in autosomal recessive polycystic kidney disease (ARPKD). Hum Mutat 23(5):453-63

5. Kim I, Fu Y, Hui K, Moeckel G, Mai W, Li C, Liang D, Zhao P, Ma J, Chen XZ, George AL Jr, Coffey RJ, Feng ZP, Wu G (2008) Fibrocystin/polyductin modulates renal tubular formation by regulating polycystin-2 expression and function. J Am Soc Nephrol 19(3): 455-68

6. Gunay-Aygun M, Font-Montgomery E, Lukose L, Tuchman Gerstein M, Piwnica-Worms K, Choyke P, Daryanani KT, Turkbey B, Fischer R, Bernardini I, Sincan M, Zhao X, Sandler NG, Roque A, Douek DC, Graf J, Huizing M, Bryant JC, Mohan P, Gahl WA, Heller T (2013) Characteristics of congenital hepatic fibrosis in a large cohort of patients with autosomal recessive polycystic kidney disease. Gastroenterology 144(1):112121

7. Büscher R, Büscher AK, Weber S, Mohr J, Hegen B, Vester U, Hoyer PF (2013) Clinical manifestations of autosomal recessive polycystic kidney disease (ARPKD): kidney-related and non-kidney-related phenotypes. Pediatr Nephrol. doi:10.1007/s00467-013-2634-1

8. Guettier C (2010) Intrahepatic biliary cystic lesions. Ann Pathol 30: 448-454

9. Goilav B, Norton K, Satlin L, Guay-Woodford L, Chen F, Magid M, Emre S, Shneider BL (2006) Predominant extrahepatic biliary disease in autosomal recessive polycystic kidney disease (ARPKD): a new association. Pediatr Transplant 10(3):294-8

10. Neumann HP, Krumme B, van Velthoven V, Orszagh M, Zerres K (1999) Multiple intracranial aneurysms in a patient with autosomal recessive polycystic kidney disease. Nephrol Dial Transplant 14: 936-939

11. Gunay-Aygun M, Font-Montgomery E, Lukose L, Tuchman M, Graf J, Bryant JC, Kleta R, Garcia A, Edwards H, Piwnica-Worms K, Adams D, Bernardini I, Fischer RE, Krasnewich D, Oden N, Ling A, Quezado Z, Zak C, Daryanani KT, Turkbey B, Choyke P, GuayWoodford LM, Gahl WA (2010) Correlation of kidney function, volume and imaging findings, and PKHD1 mutations in 73 patients with autosomal recessive polycystic kidney disease. Clin J Am Soc Nephrol 5(6):972-984

12. Taneda S, Honda K, Aoki A, Nitta K, Tamura T, Yoshioka Y, Oda H (2012) An autopsy case of clinically un-diagnosed autosomal recessive polycystic kidney disease in 77-year-old male. Pathol Int 62(12): 811-8116

13. Fonck C, Chauveau D, Gagnadoux MF, Pirson Y, Grünfeld JP (2001) Autosomal recessive polycystic kidney disease in adulthood. Nephrol Dial Transplant 16(8):164816-52

14. Zerres K, Mücher G, Becker J, Steinkamm C, Rudnik-Schöneborn S, Heikkilä P, Rapola J, Salonen R, Germino GG, Onuchic L, Somlo S, Avner ED, Harman LA, Stockwin JM, Guay-Woodford LM (1998) Prenatal diagnosis of autosomal recessive polycystic kidney disease (ARPKD): molecular genetics, clinical experience, and fetal morphology. Am J Med Genet 76(2):137-144
15. Desmet VJ (1992) Congenital diseases of intrahepatic bile ducts: variations on the theme "ductal plate malformation". Hepatology 16(4):1069-1083

16. Venkatanarasimha N, Thomas R, Armstrong EM, Shirley JF, Fox BM, Jackson SA (2011) Imaging features of ductal plate malformations in adult. Clin Radiol 66(11):1086-1093

17. Moser P (2011) Diagnosis and management of acute cholangitis. Curr Gastroenterol Rep 13:166-172

18. Beaunoyer M, Snehal M, Li L, Concepcion W, Salvatierra O Jr, Sarwal M (2007) Optimizing outcomes for neonatal ARPKD. Pediatr Transplant 11:267-271

19. Shneider BL, Magid MS (2005) Liver disease in autosomal recessive polycystic kidney disease. Pediatr Transplant 9:634-639

20. Khan K, Schwarzenberg SJ, Sharp HL, Matas AJ, Chavers BM (2002) Morbidity from congenital hepatic fibrosis after renal transplantation for autosomal recessive polycystic kidney disease. Am J Transplant 2:360-365

21. Davis ID, Ho M, Hupertz V, Avner ED (2003) Survival of childhood polycystic kidney disease following renal transplantation: the impact of advanced hepatobiliary disease. Pediatr Transplant 7(5):364-369

22. Abdul Wahab A, Al-Mansoori M, El-Hawli M, Kini V (2013) Unexplained cyanosis revealing hepatopulmonary syndrome in a child with asymptomatic congenital hepatic fibrosis: a case report. J Med Case Rep 7(1):120

23. Kaymakoglu S, Kahraman T, Kudat H, Demir K, Cakaloglu Y, Adalet I, Dincer D, Besisik F, Boztas G, Sözen AB, Mungan Z, Okten A (2003) Hepatopulmonary syndrome in noncirrhotic portal hypertensive patients. Dig Dis Sci 48(3):556-560

24. Sari S, Oguz D, Sucak T, Dalgic B, Atasever T (2012) Hepatopulmonary syndrome in children with cirrhotic and noncirrhotic portal hypertension: a single-center experience. Dig Dis Sci 57(1):175-181

25. Gunay-Aygun M, Avner ED, Bacallao RL, Choyke PL, Flynn JT, Germino GG, Guay-Woodford L, Harris P, Heller T, Ingelfinger J, Kaskel F, Kleta R, LaRusso NF, Mohan P, Pazour GJ, Shneider BL, Torres VE, Wilson P, Zak C, Zhou J, Gahl WA (2006) Autosomal recessive polycystic kidney disease and congenital hepatic fibrosis: summary statement of a first National Institutes of Health/Office of Rare Diseases conference. J Pediatr 149(2):159-164

26. Rawat D, Kelly DA, Milford DV, Sharif K, Lloyd C, McKiernan PJ (2013) Phenotypic variation and long-term outcome in children with congenital hepatic fibrosis. J Pediatr Gastroenterol Nutr 57(2):161-166

27. Shneider BL, Bosch J, de Franchis R, Emre SH, Groszmann RJ, Ling SC, Lorenz JM, Squires RH, Superina RA, Thompson AE, Mazariegos GV, expert panel of the Children's Hospital of Pittsburgh of UPMC (2012) Portal hypertension in children: expert pediatric opinion on the report of the Baveno v Consensus Workshop on Methodology of Diagnosis and Therapy in Portal Hypertension. Pediatr Transplant 16(5):426-437

28. dos Santos JM, Ferreira AR, Fagundes ED, Ferreira AP, Ferreira LS, Magalhães MC, Bittencourt PF, Carvalho SD, Figueiredo Filho PP, Penna FJ (2013) Endoscopic and pharmacological secondary prophylaxis in children and adolescents with esophageal varices. J Pediatr Gastroenterol Nutr 56(1):93-98

29. de Ville de Goyet J, D’Ambrosio G, Grimaldi C (2012) Surgical management of portal hypertension in children. Semin Pediatr Surg 21(3):219-32

30. Botha JF, Campos BD, Grant WJ, Horslen SP, Sudan DL, Shaw BW Jr, Langnas AN (2004) Portosystemic shunts in children: a 15-year experience. J Am Coll Surg 199(2):179-85

31. Lillegard JB, Hanna AM, McKenzie TJ, Moir CR, Ishitani MB, Nagorney DM (2010) A single-institution review of portosystemic shunts in children: an ongoing discussion. HPB Surg 2010:964597

32. Mazzaferro V, Todo S, Tzakis AG, Stieber AC, Makowka L, Starzl TE (1990) Liver transplantation in patients with previous portasystemic shunt. Am J Surg 160(1):111-6 
33. Benador N, Grimm P, Lavine J, Rosenthal P, Reznik V, Lemire J (2001) Transjugular intrahepatic portosystemic shunt prior to renal transplantation in a child with autosomal-recessive polycystic kidney disease and portal hypertension: a case report. Pediatr Transplant $5(3): 210-4$

34. Cornelis HC, Dejong CH, Nicolaas EP, Deutz NE, Soeters PB (1993) Metabolic adaptation of the kidney to hyperammonemia during chronic liver insufficiency in the rat. Hepatology 18:890-902

35. Olde Damink SW, Jalan R, Dejong CH (2009) Interorgan ammonia trafficking in liver disease. Metab Brain Dis 24(1):169-81

36. Cornelis HC, Dejong CH, Nicolaas EP, Deutz NE, Soeters PB (1993) Renal ammonia and glutamine metabolism during liver insufficiency-induced hyperammonemia in the rat. J Clin Invest 92: 2834-2840

37. Tsimaratos M, Cloarec S, Roquelaure B, Retornaz K, Picon G, Chabrol B, Guys JM, Sarles J, Nivet H (2000) Chronic renal failure and portal hypertension - is portosystemic shunt indicated. Pediatr Nephrol 14:856-8

38. Kashtan CE, Primack WA, Kainer G, Rosenberg AR, McDonald RA, Warady BA (1999) Recurrent bacteremia with enteric pathogens in recessive polycystic kidney disease. Pediatr Nephrol 13(8):678-682

39. Ko JS, Yi NJ, Suh KS, Seo JK (2012) Pediatric liver transplantation for fibropolycystic liver disease. Pediatr Transplant 16(2):195-200

40. Ananthakrishnan AN, Saeian K (2007) Caroli's disease: identification and treatment strategy. Curr Gastroenterol Rep 9(2):151-155

41. Sutherland SM, Alexander SR, Sarwal MM, Berquist WE, Concepcion W (2008) Combined liver kidney transplantation in children: indications and outcome. Pediatr Transplant 12:835-846

42. Chava SP, Singh B, Pal S, Dhawan A, Heaton ND (2009) Indications for combined liver and kidney transplantation in children. Pediatr Transplant 13(6):661-669

43. Jalanko H, Pakarinen M (2014) Combined liver and kidney transplantation in children. Pediatr Nephrol 29:805-814

44. Ellis SR, Hulton SA, McKiernan PJ, De Ville de Goyet J, Kelly DA (2001) Combined liver-kidney transplantation for primary hyperoxaluria type 1 in young children. Nephrol Dial Transplant $16: 348-352$

45. Perera MT, Silva MA, Sharif K, McKiernan PJ, Kelly DA, Lloyd C, Milford DV, Mayer DA, Mirza DF (2009) Improved outcomes of combined liver and kidney transplants in small children $(15 \mathrm{~kg})$. Transplantation 88:711-715

46. Millan MT, Berquist WE, So SK, Sarwal MM, Wayman KI, Cox KL, Filler G, Salvatierra O Jr, Esquivel CO (2003) One hundred percent patient and kidney allograft survival with simultaneous liver and kidney transplantation in infants with primary hyperoxaluria: a single-center experience. Transplantation 76:1458

47. Harps E, Brinkert F, Ganschow R, Briem-Richter A, van Husen M, Schmidtke S, Herden U, Nashan B, Fischer L, Kemper MJ (2011) Immediate postoperative intensive care treatment of pediatric combined liver-kidney transplantation: outcome and prognostic factors. Transplantation 91(10):1127-31

48. Telega G, Cronin D, Avner ED (2013) New approaches to the autosomal recessive polycystic kidney disease patient with dual kidney-liver complications. Pediatr Transplant 17(4):328-35

49. Hosgood SA, Yang B, Bagul A, Mohamed IH, Nicholson ML (2010) A comparison of hypothermic machine perfusion versus static cold storage in an experimental model of renal ischemia reperfusion injury. Transplantation 89(7):830-7

50. Moers C, Smits JM, Maathuis MH, Treckmann J, van Gelder F, Napieralski BP, van Kasterop-Kutz M, van der Heide JJ, Squifflet JP, van Heurn E, Kirste GR, Rahmel A, Leuvenink HG, Paul A, Pirenne J, Ploeg RJ (2009) Machine perfusion or cold storage in deceased-donor kidney transplantation. N Engl J Med 360(1):7-19
51. Makowka L, Stieber AC, Sher L, Kahn D, Mieles L, Bowman J, Marsh JW, Starzl TE (1988) Surgical technique of orthotopic liver transplantation. Gastroenterol Clin N Am 17(1):33-51

52. Tzakis A, Todo S, Starzl TE (1989) Orthotopic liver transplantation with preservation of the inferior vena cava. Ann Surg 210:649

53. Lázaro JL, Charco R, Revhaug A, Murio E, Balsells J, Hidalgo E, Mora A, Cortés C, Margarit C (1997) Hemodynamics in human liver transplantation with inferior vena cava preservation. Transplant Proc 29(7):2851-2

54. Levi DM, Pararas N, Tzakis AG, Nishida S, Tryphonopoulos P, Gonzalez-Pinto I, Tekin A, Selvaggi G, Livingstone AS (2012) Liver transplantation with preservation of the inferior vena cava: lessons learned through 2,000 cases. J Am Coll Surg 214(4):691-8

55. Vieira de Melo PS, Miranda LE, Batista LL, Neto OC, Amorim AG, Sabat BD, Cândido HL, Adeodato LC, Lemos RS, Carvalho GL, Lacerda CM (2011) Orthotopic liver transplantation without venovenous bypass using the conventional and piggyback techniques. Transplant Proc 43(4):1327-33

56. Angelis M, Pegelow CH, Khan FA, Verzaro R, Tzakis AG (2001) En bloc heterotopic auxiliary liver and bilateral renal transplant in a patient with homozygous protein C deficiency. J Pediatr 138:120 122

57. McGuire MM, Jones BA, Hull MA, Misra MV, Smithers CJ, Feins NR, Jenkins RL, Lillehei CW, Harmon WE, Jonas MM, Kim HB (2011) Combined en bloc liver-double kidney transplantation in an infant with IVC thrombosis. Pediatr Transplant 15(7):E142-144

58. Spiro MD, Eilers H (2013) Intraoperative care of the transplant patient. Anesthesiol Clin 31(4):705-21

59. Ma Y, Wang GD, He XS, Li Q, Li JL, Zhu XF, Wang CX (2010) Simultaneous liver and kidney transplantation: analysis of a singlecenter experience. Chin Med J 123(10):1259-1263

60. Ashworth A, Klein AA (2010) Cell salvage as part of a blood conservation strategy in anaesthesia. Br J Anaesth 105(4):401-416

61. Xia VW, Ghobrial RM, Du B, Chen T, Hu KQ, Hiatt JR, Busuttil RW, Steadman RH (2007) Predictors of hyperkalemia in the prereperfusion, early postreperfusion, and late postreperfusion periods during adult liver transplantation. Anesth Analg 105(3):780 785

62. Sedra AH, Strum E (2011) The role of intraoperative hemodialysis in liver transplant patients. Curr Opin Organ Transplant 16(3):323-325

63. Simpson N, Cho YW, Cicciarelli JC, Selby RR, Fong TL (2006) Comparison of renal allograft outcomes in combined liver-kidney transplantation versus subsequent kidney transplantation in liver transplant recipients: analysis of UNOS Database. Transplantation 82(10):1298-1303

64. Fung J, Makowka L, Tzakis A, Klintmalm G, Duquesnoy R, Gordon R, Todo S, Griffin M, Starzl T (1988) Combined liver-kidney transplantation: analysis of patients with preformed lymphocytotoxic antibody. Transplant Proc 20(1 Suppl 1):88-91

65. Rasmussen A, Davies HFS, Jamieson NV, Evans DB, Calne RY (1995) Combined transplantation of liver and kidney from the same donor protects the kidney from rejection and improves kidney graft survival. Transplantation 59(6):919-921

\section{Answers}

1. d

2. c

3. $d$

4. e

5. c 